\author{
I. DOCUMENTACIÓN \\ I. Documentation
}

\title{
ANÁLISIS DE LAS SERIES DOCUMENTALES PARA EL ESTUDIO DE LA HISTORIA DE LA EDUCACIÓN EN LOS ARCHIVOS HISTÓRICOS DE SEMINARIOS: EL EJEMPLO DEL ARCHIVO DEL SEMINARIO SAN ATÓN DE BADAJOZ
}

Analysis of the documentary series for the study of the bistory of education in the historical files of seminars: the example of the file of the seminar San Atón of Badajoz

Agustín Vivas Moreno

Facultad de Documentación y Comunicación. Universidad de Extremadura

Correo-e: avivas@alcazaba.unex.es

Francisco González Lozano

Seminario Metropolitano San Atón de Badajoz

Correo-e: fglozano@hotmail.com

Guadalupe Pérez Ortiz

Seminario Metropolitano San Atón de Badajoz

Correo-e: mgperort@alcazaba.unex.es

Recepción: 6 de abril de 20I5. Envío a informantes: II de abril de 2015.

Fecha de aceptación definitiva: 26 de octubre de 2015

Resumen: El carácter educativo del Seminario Metropolitano San Atón de Badajoz ha generado, a lo largo de trescientos cincuenta años de trayectoria, testimonios escritos de necesaria consulta para la historia educativa. El archivo del Seminario 
Metropolitano San Atón custodia documentación aún desconocida para la elaboración de futuros trabajos sobre educación. El investigador que ahonde en la educación y en los métodos pedagógicos entre los siglos XVII al XX necesariamente volverá su mirada a este interesante archivo dado que el Seminario de Badajoz asumió durante parte de su historia ser la sede del primer centro de enseñanzas secundarias de Badajoz y la primera universidad de Extremadura, por consiguiente, su archivo alberga contenidos vitales para el estudio de la educación extremeña y de los alumnos que pasaron por sus aulas, permitiendo el trazado de investigaciones de heterogénea naturaleza.

Palabras Clave: historia de la educación; iglesia; educación; contenidos educativos y pedagógicos; Seminario Metropolitano San Atón.

Aвstract: The educational character of the Metropolitan Seminary San Atón of Badajoz has generated, over three hundred and fifty years of history, written testimonies from consultation necessary for the educational history. The file of the Metropolitan Seminary San Atón custody documentation still unknown for the development of future work on education. The educational character of the institution has generated written testimonies of required consultation for the history. The researcher who studied education and pedagogy from the $17^{\text {th }}$ to $20^{\text {th }}$ centuries will find a lot of documentation in our file since Badajoz Seminar took over part of its history to host the first center of teaching secondary Badajoz and the first university of Extremadura, therefore its contents archive contains vital for the study of Extremadura education.

KEY WORDS: Educations contents; pedagogical contents; education; worship; Seminario Metropolitano San Atón.

\section{Introducción}

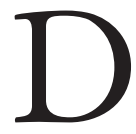

E SOBRA ES CONOCIDA LA LABOR EDUCATIVA realizada por la Iglesia en sus veinte siglos de trayectoria. Su finalidad se asentaba en el mandato de Jesucristo a sus apóstoles de «id y enseñad a todos los pueblos» el evangelio que Él mismo les había transmitido. El paso de los siglos reclamó la creación de una nueva institución que reglara adecuadamente la formación de aquellos que estaban al frente de las iglesias particulares, los sacerdotes. Basándose en las experiencias de siglos anteriores, el concilio de Trento ${ }^{\mathrm{I}}$ ordenó la creación de los seminarios conciliares como centros eclesiales educativos destinados a tal fin.

El presente trabajo centra su atención en el Seminario Conciliar de San Atón desde su fundación en I664 y hasta nuestros días. Su trayectoria educativa ha sido un referente en la cultura extremeña. Su prestigiosa influencia formativa, humanística y religiosa ha dejado una huella indeleble en la sociedad a la que sirvió

Concilium Tridentinum, Diariorum, Actorum, Epistularum, Tractatuum nova Collectio Ix, I90I, pp. 628-663. 
ANÁLISIS DE LAS SERIES DOCUMENTALES PARA EL ESTUDIO DE LA HISTORIA DE LA EDUCACIÓN EN LOS ARCHIVOS HISTÓRICOS DE SEMINARIOS ... AGUSTÍN VIVAS, FRANCISCO GONZÁLEZ Y GUADALUPE PÉREZ

como institución educativa eclesial. No perdiendo su identidad primaria, esto es, la formación de los futuros clérigos, desarrolló su labor en favor de todos los que llamaron a sus puertas, especialmente de los niños más desfavorecidos.

La causa principal que nos ha llevado al desarrollo de esta investigación es dar a conocer una de las entidades más antigua y de más importancia en el panorama educativo y cultural de Extremadura, el Seminario Metropolitano de San Atón de Badajoz. Las posibilidades para este fin son muchas y muy variadas, como los recursos con los que ha contado el Seminario en sus más de tres siglos de historia. De entre todos ellos, nos hemos centrado en uno de los pilares estructurales que constituyen el Seminario, su archivo. Entendemos que en él se van a dar cabida los testimonios escritos que han permitido el desarrollo del centro en su vertiente educativa, además de en otros niveles: económicos, culturales, espirituales, litúrgicos, etc., y que permiten al investigador constatar la relevancia de esta institución. Los objetivos fundamentales de este trabajo son:

I. Dar a conocer el Seminario Metropolitano de San Atón desde la documentación contenida en sus archivos. Para ello hemos desarrollado, en primer lugar, el cuadro de clasificación del fondo histórico del archivo, herramienta documental de gran utilidad para el conocimiento de los contenidos archivísticos, de la que carecía la entidad hasta hace unos meses².

2. Mostrar la importancia que esta entidad tuvo durante los siglos XVII-XIX en el panorama educativo de Extremadura, cuando asume ser el primer centro de enseñanza secundaria en Badajoz y la primera universidad de Extremadura; siempre tomando como referencia su archivo.

3. Dar a conocer los múltiples contenidos educativos y sobre alumnado que aparecen en el cuadro de clasificación del archivo, permitiendo a los investigadores ofrecer variadas líneas de trabajo que tengan como sustento la citada documentación. Campos de trabajo de variada naturaleza, tales como: estudios de alumnado, de personajes ilustres, sobre cuestiones genealógicas, trazado de biografías de alumnos y profesores, sistemas de enseñanza, planes de estudio, etc.

Para alcanzar los objetivos anteriormente expuestos se han empleado diversos recursos metodológicos, que han dado lugar a una serie de resultados constatables, que serán expuestos al final del artículo. En primer lugar, el uso de las técnicas archivísticas. Dichas técnicas se basaron en el análisis exhaustivo de cada una de las piezas documentales (documentos sueltos) y las unidades archivísticas (expedientes), tanto en sus caracteres internos como externos, haciendo especial hincapié en aquellos documentos que tenían que ver con cuestiones educativas. De la aplicación del método archivístico resulta un fondo documental que presenta una disposición organicista donde cada uno de los documentos sólo tiene sentido en

Fuentes Nogales, M. C. y Pérez Ortiz, G.: Guía del Archivo del Seminario Metropolitano San Atón, Badajoz, Seminario Metropolitano San Atón, 2014. 
ANÁLISIS DE LAS SERIES DOCUMENTALES PARA EL ESTUDIO DE LA HISTORIA DE LA EDUCACIÓN EN LOS ARCHIVOS HISTÓRICOS DE SEMINARIOS ... AGUSTÍN VIVAS, FRANCISCO GONZÁLEZ Y GUADALUPE PÉREZ

relación con los demás, y preparado para ser consultado por el usuario. En segundo término, el análisis histórico nos permite examinar la documentación desde el punto de vista del investigador interesado en la historia, fundamentalmente en la historia educativa y pedagógica de Extremadura desde el siglo XVII-XIX. Por tanto, ofrecemos a continuación contenidos útiles para el historiador y el pedagogo que deseen hacer un estudio serio de la cultura extremeña en los siglos referidos. Como ya hemos señalado el Seminario San Atón fue el primer centro universitario de Extremadura, la sede del primer instituto de enseñanza secundaria en la ciudad de Badajoz, cuna cultural de miles de niños que elevaron la grandeza de esta tierra mediante la formación académica y promotor insigne de una educación integral debidamente organizada y adecuadamente estructurada.

\section{Aproximación a la historia de la educación en los seminarios conciliares: breve estado de la cuestión}

El concilio de Trento fue el decimonoveno concilio ecuménico de la Iglesia católica y se desarrolló en tres fases entre los años 1545 y i563. La reunión de dignidades eclesiásticas cerró un período de desconcierto de los fieles y de notables irregularidades en la gestión temporal de la Iglesia y en la formación de los presbíteros, e inició una etapa de claridad doctrinal y de disciplina y centralización que culminaría siglos después en el concilio Vaticano II. A tenor del decreto De Seminariorum erectione et regimine, de 15 de julio de 1563 , se dictaminó la creación en todas las diócesis de seminarios, ofreciendo unas normas generales y criterios de selección y de formación de los candidatos al sacerdocio. El texto del concilio rezaba así:

Siendo inclinada la adolescencia a seguir los deleites mundanales, si no se la dirige rectamente, y no perseverando jamás en la perfecta observancia de la disciplina eclesiástica, sin un grandísimo y especialísimo auxilio de Dios, a no ser que desde sus más tiernos años y antes que los hábitos viciosos lleguen a dominar todo el hombre, se les dé crianza conforme a la piedad y religión.

Establece el santo Concilio que todas las catedrales, metropolitanas, e iglesias mayores que estas tengan obligación de mantener, y educar religiosamente, e instruir en la disciplina eclesiástica, según las facultades y extensión de la diócesis, cierto número de jóvenes de la misma ciudad y diócesis, o al no haberlos en estas, de la misma provincia, en un colegio situado cerca de las mismas iglesias, o en otro lugar oportuno a elección del Obispo 3 .

El nacimiento de una nueva institución orientada a la formación de los clérigos nos conduce directamente a la situación de la Iglesia católica en un período de confusión doctrinal. La teología católica comenzaba a resquebrajarse, por lo que fue necesario un impulso a la formación sacerdotal. Las graves carencias formativas de

\section{Concilio de Trento, Sesión xxıI, Decreto De Reformatione, capítulo I8.}


ANÁLISIS DE LAS SERIES DOCUMENTALES PARA EL ESTUDIO DE LA HISTORIA DE LA EDUCACIÓN EN LOS ARCHIVOS HISTÓRICOS DE SEMINARIOS ... AGUSTÍN VIVAS, FRANCISCO GONZÁLEZ Y GUADALUPE PÉREZ

la Iglesia aquejaban a la misma clerecía. Y, así, urgía la implantación de seminarios que llevaran a cabo esta misión. Si bien es cierto que Trento pretendió, más bien, universalizar la formación doctrinal de los laicos en orden a cimentar una sociedad moderna virtuosa ${ }^{4}$. Pese al mandato del Concilio, que ordenaba que los seminarios se erigieran prope ecclesiam, donde los seminaristas se formaran en la pastoral y la liturgia al amparo y ejemplo de la catedral, no podemos obviar que la realidad española, favorecida por Felipe II y promovida por universidades y colegios universitarios de donde había salido toda la clerecía presente en el Concilio, tendió a fundar los seminarios prope universitatem, esto es, como alimentadores de las universidades y con una concepción y modelo sacerdotal más culto e intelectual's Se presentaba así esta nueva institución como un internado, con enseñanza especial y disciplina particular, siguiendo unos actos de piedad propios de candidatos a órdenes sagradas, bajo la autoridad del obispo de la diócesis, representado en la figura del rector. Una decisión conciliar trascendental, tras la que comenzaría la andadura de un nuevo centro educativo eclesiástico: el Seminario con una doble finalidad: «Hacer y educar sacerdotes, abundantes e idóneos en virtud y ciencia» ${ }^{6}$. De esta manera se decreta la creación y la obligatoriedad de los seminarios en las diócesis, lo cual es confirmado por el papa Pío IV7?.

Durante la segunda mitad del siglo xvi y hasta finales del siglo xvir, la aplicación del decreto conciliar fue urgida por todos. Los prelados tridentinos no se propusieron ser originales en la creación de esta nueva institución ${ }^{8}$. No obstante, comienza a usarse, a partir del siglo xvi, la palabra seminario, en lugar de la habitual, colegio, para referirse a los centros de formación sacerdotal. El paso de los siglos demandó actualizaciones constantes en la formación de los futuros sacerdotes.

La producción bibliográfica que recoge la trayectoria más general sobre los seminarios es abundante. El primer estudio sistemático lo encontramos con Juan de Giovanni, Historia de los seminarios clericales, traducida por el maestro fray Bernardo Agustín de Zamora, por mandato del obispo de Salamanca don Felipe Beltrán en la imprenta de Francisco Rico, i778. Pero será el final del siglo xix y el principio del siglo xx los que vean la publicación de numerosas obras de referencia para la comprensión y el estudio en profundidad de estas instituciones;;

$4 C f r$. Vergara Ciordia, J.: «Mentalidad cristiana y pensamiento pedagógico de la Iglesia en España», en BARTOlomé MarTínez, B. (coord.): Historia de la acción educadora de la Iglesia en España, t. I, Madrid, BAC, 1996, pp. 499-526.

Cfr. Martín Hernández, F.: «La formación del clero en los siglos xvil y xviII», en García Villoslada, R. (coord.): Historia de la Iglesia en España, t. Iv, Madrid, Bac, 1979, p. 525.

6 Sesión III, cap. XVII.

Rops, D.: Historia de la Iglesia, vol. viI, Madrid, 1970, pp. I04 y ss.

8 Vergara Ciordia, J.: Historia y pedagogía del Seminario Conciliar en Hispanoamérica (I563I800), Madrid, Dykinson, 2004, pp. 38-39.

9 Castro Alonso, M.: Enseñanza eclesiástica en España, Valladolid, Imprenta José Manuel de la Cuesta, i898; Fernández Conde, M.: España y los seminarios tridentinos, Madrid, Consejo Superior de Investigaciones Científicas, 1948; idem: El decreto tridentino sobre seminarios y su aplicación en España hasta el año I723, Madrid, 1948; MARTín Hernández, F.: Los seminarios españoles: Historia y pedagogía, Salamanca, Sígueme, 1964; idem: Los seminarios españoles en la época de la 
ANÁLISIS DE LAS SERIES DOCUMENTALES PARA EL ESTUDIO DE LA HISTORIA DE LA EDUCACIÓN EN LOS ARCHIVOS HISTÓRICOS DE SEMINARIOS ... AGUSTÍN VIVAS, FRANCISCO GONZÁLEZ Y GUADALUPE PÉREZ

que deberán ser entendidas desde la generalidad de las mismas, es decir, el aspecto educativo en los seminarios será abordado en ellas como un tema más a tratar en el marco de desarrollo de estas publicaciones.

A estas investigaciones generales hemos de sumar otros estudios particulares que analizan épocas posteriores, en concreto entre el concordato de Isabel II y el concilio Vaticano II; se trata, por tanto, de documentación de necesaria consulta para seguir completando las directrices y trayectorias de los seminarios iniciadas en el siglo $\mathrm{XvI}^{\mathrm{I}}$. Así como otros estudios que se centran en cuestiones relativas a los seminarios españoles a partir de estas fechas ${ }^{\mathrm{II}}$ que son completados con los análisis específicos sobre la situación de estos centros en los siglos $\mathrm{XIX}^{-\mathrm{XX}^{12}}$ y que nos permiten comprender el desarrollo global de estas instituciones desde su nacimiento a épocas actuales.

En el año i955 sale a la luz una revista de estudios y documentos sobre temas sacerdotales que era publicada por el Colegio Mayor «Maestro Ávila» de Salamanca, perteneciente a la Hermandad de Sacerdotes Operarios Diocesanos. Con

Ilustración: Ensayo de una pedagogía eclesiástica en el siglo XVIII, Madrid, Instituto Enrique Flórez, 1973; Martín Hernández, F. y Martín Hernández, J.: Los seminarios españoles en la época de la Ilustración: Ensayo de una pedagogía eclesiástica en el siglo XVIII, Madrid, Consejo Superior de Investigaciones Científicas, 1973; SÁnChez Aliseda, C.: La doctrina de la Iglesia sobre los Seminarios desde Trento hasta nuestros días, Granada, Facultad de Teología, 1942.

10 AA. vv.: Estudios, seminarios y pastoral en un siglo de historia de España (I882-1992), Roma, Colegio Pontificio Español, i992; Aguirre Prado, L.: La Iglesia y la guerra civil, Madrid, Servicio Informativo Español, 1964; ANDRÉs MARTín, M.: La supresión de las facultades de teología en las universidades españolas (1845-1855), Burgos, 1976; AzNar, S.: La Revolución Española y Las Vocaciones Eclesiásticas, Madrid, Instituto de Estudios Políticos, 1949; Bartolomé Martínez, B.: Historia de la acción educadora de la Iglesia en España, vol. II, Madrid, BAC, I997; CÁrcel OrTí, V.: León XIII y los Católicos Españoles, Pamplona, 1988; Cuenca Toribio, J. M.: Historia de España. t. II, Barcelona, 1973; Faubell Zapata, V.: «Autonomía y universidades de la Iglesia en España», Revista de Ciencias de la Educación, 154 (1993), pp. 213-219; Gómez Pérez, R.: Politica y religión en el régimen de Franco, Barcelona, 1976; GonzÁLEz DE CARDEDAL, O.: ¿ Crisis de seminarios o crisis de sacerdotes?, Madrid, Marova, 1967; PÉRez de Alhama, J.: La Iglesia y el estado español. Estudio histórico-jurídico a través del concordato de I85I, Madrid, 1967; TuRín, I.: La educación y la escuela en España de 1874 a 1902, Madrid, i967; Martín Velasco, J. D.: Avatares del clero español en los últimos años, Santander, Sal Terrae, i996; Vergara Ciordia, J. y Comellas Gutiérrez, B.: «El seminario conciliar en las relaciones Iglesia-Estado en España desde Trento al Concilio Vaticano II», Revista de Estudios Extremeños, 70/n. ${ }^{\circ}$ extraordinario (20I4), pp. 553-596; Vergara Ciordia, J. y Rodríguez Sedano, A.: «Devenir institucional de la formación sacerdotal hasta el Concilio de Trento", Revista de Estudios Extremeños, $70 / \mathrm{n} .^{\circ}$ extraordinario (20I4), pp. 5II-552.

"Infantes Florido, J. A.: Un Seminario de su siglo: entre la Inquisición y las Luces, Las Palmas, I977; Martín Hernández, F.: «La formación del clero en los siglos XviI y XviII...», op. cit.; Martín Hernández, F.: Los Seminarios españoles en la época de la Ilustración.., op. cit.

${ }_{12}$ Cuenca Toribio, J. M.: «Notas para el estudio de los seminarios españoles en el pontificado de Pío IX», Saitabi, 23 (1973), pp. 5I-88; OrLANDIs, J.: «Informe de la Visita apostólica a los seminarios españoles en 1933-1934. Edición del Informe y estudio sobre "La formación sacerdotal en España" (1850-1939)», Anuario Historia de la Iglesia, I6 (2007), pp. 517-518; Tineo, P.: «La formación teológica en los seminarios españoles (1890-1925)», Anuario de Historia de la Iglesia, 2 (1993), pp. 45-96; VÁzquez Vilanova, J. A.: «Los estudios en los seminarios españoles en el siglo XIX», Hispania Sacra 54, 109 (2002), pp. 227-242. 
ANÁLISIS DE LAS SERIES DOCUMENTALES PARA EL ESTUDIO DE LA HISTORIA DE LA EDUCACIÓN EN LOS ARCHIVOS HISTÓRICOS DE SEMINARIOS ... AGUSTÍN VIVAS, FRANCISCO GONZÁLEZ Y GUADALUPE PÉREZ

una periodicidad inicial de dos volúmenes al año la temática que contiene versa sobre estudios relacionados con el sacerdocio católico y con la formación de los candidatos al mismo, las vocaciones, los métodos pedagógicos de educación sacerdotal, su formación intelectual, la historia de los seminarios mayores, información nacional y extranjera de los principales acontecimientos y novedades dentro del ámbito de pedagogía eclesiástica, documentos oficiales de las distintas Congregaciones sobre formación sacerdotal. La revista Seminarios aporta a la visión histórica un amplio elenco de artículos y monográficos sobre esta institución conciliar ${ }^{13}$.

Particularmente importante para nuestro trabajo es que, junto a estas monografías generales, encontramos otras específicas sobre cuestiones pedagógicas y educativas, que ya no muestran la generalidad de los seminarios sino que se centran en casos particulares de seminarios diocesanos que iluminan la trayectoria y la aplicación de las normas conciliares a las diócesis españolas o hispanoamericanas ${ }^{14}$ en relación a cuestiones educativas.

13 Álvarez Arroyo, J.: «Función de la Filosofía en la formación eclesiástica», Seminarios, 26 (I965), pp. 337-356; Amenos, J. M.: «El fomento de las vocaciones eclesiásticas en España durante la segunda mitad del siglo XIX», Seminarios, I (1955), pp. 65 y ss.; CÁrcel OrTí, V.: «Estado material, académico y moral de los seminarios españoles durante el siglo XIX», Seminarios, 77-78 (1980), pp. 267-275; "Informe sobre la situación de los seminarios en España hasta el 3I de diciembre de I89I», Seminarios, 26 (1980), pp. 376-387; Gandarillas, F. M.: «El Concilio Vaticano II y Los Seminarios Menores», Seminarios, 29 (1966), pp. 393-4I5; Garrone, G. M.: «Discurso», Seminarios, I7 (197I), pp. I27-I4I; Gioardani, N.: «La carpeta personal en los seminarios», Seminarios, 29 (1966), pp. 417-468; Hernández Caser, A.: «La formación espiritual en la exhortación Pastores Dabo Vobis», Seminarios, 39 (1993), pp. 303-329; MÁrTIL, G.: «Los seminarios en el Concilio Vaticano II. Historia y comentario», Seminarios, 28 (I966), pp. II-I27; «Los seminarios hoy. Problemas de formación sacerdotal», Seminarios, 17 (1954), pp. II-217; Martín Hernández, F.: «La hermandad de sacerdotes operarios diocesanos y los seminarios españoles. Finales del siglo xIx y principios del XX», Seminarios, 77-78 (1980), pp. 46I-484; Osés J.: «Problemas actuales de nuestros seminarios», Seminarios, 34 (1968), pp. I3I-I34; PÉreZ, I.: «Misión actual fundamental de los profesores de filosofía en los seminarios mayores y centros de estudios equivalentes», Seminarios, 30 (1996), pp. 549-580; SÁnCHEZ, U.: «El rector del seminario. Algunos aspectos de su figura jurídica», Seminarios, 25 (1965), pp. 157-201; SuQuía, A.: «Sacerdotes nuevos para un nuevo mundo. Discurso en la inauguración de la LI asamblea plenaria de la conferencia episcopal española», Seminarios, 36 (I990), pp. 89-I04; TARAncón, V. E.: «El seminario ante el momento actual de la iglesia», Seminarios, 26 (1965), pp. 477-490.

${ }_{14}$ Abad, C. M. a. El Seminario Pontificio de Comillas: historia de su fundación y primero años, (I88I-1925), Madrid, Tip. Católica de A. Fontana, I928; Comellas Gutiérrez, B.: «El devenir pedagógico de los seminarios conciliares españoles en la Edad Contemporánea», Hispania Sacra, 66/ extraordinario I/ (20I4), pp. 339-37i; Díaz SÁnchez Cid, J. R.: El Seminario conciliar de San Ildefonso de Toledo: cien años de historia (I889-1989), Toledo, Grafitol, i99i; Espinosa Sarmiento, J. M.: El seminario de El Escorial en tiempos de San Antonio María Claret (I861-I868), Navarra, Eunsa, 1995; García Sánchez, J.: Apuntes históricos del Seminario Conciliar de San Cayetano de Ciudad Rodrigo: un testimonio de la impronta institucional y política de Campomanes, Oviedo, Ediciones de la Universidad, 2009; Hernández Figueiredo, J. R.: El Seminario Conciliar de San Fernando de Ourense (I804-I952), Orense, Diputación Provincial, 2004; Martín Hernández, F.: Los Seminarios españoles. Historia y pedagogía (I563-1700), Salamanca, I963; Martín Riego, M.: La formación intelectual en el Seminario conciliar de Sevilla (I83I-I93I), Navarra, Servicio de publicaciones de la Universidad, I994; Martín ZúÑiga, F. y Vico Monteoliva, M.: «El Colegio de teólogos y juristas San Dionisio de Aeropagita del Sacro-Monte de Granada (I752-1800)", Historia de la Educación, 3 (1984), 
ANÁLISIS DE LAS SERIES DOCUMENTALES PARA EL ESTUDIO DE LA HISTORIA DE LA EDUCACIÓN EN LOS ARCHIVOS HISTÓRICOS DE SEMINARIOS ... AGUSTÍN VIVAS, FRANCISCO GONZÁLEZ Y GUADALUPE PÉREZ

Nos encontramos, así pues, ante una de las instituciones eclesiales educativas más señeras de la historia. Su misión fundamental fue aclarada desde el principio: la educación de los niños y jóvenes que aspiraban a la clerecía. Desde esta finalidad educativa podremos comprender, interpretar y valorar la documentación custodiada en sus archivos, método válido para la investigación históricopedagógica.

\section{El archivo del Seminario Metropolitano San Atón de Badajoz y su documentación sobre Educación}

\section{I. Aproximación a la bistoria del archivo}

La Iglesia, conocedora del rico patrimonio bibliográfico y documental que atesoran sus bibliotecas y archivos, ha demostrado interés en la salvaguarda de los mismos. En relación a los archivos, en un primer momento se pretendía únicamente que fueran elementos que permitieran intemporalizar la doctrina; posteriormente, los archiveros eclesiásticos se encargaron de describir la documentación en ellos conservada, para que los documentos ubicados en archivos de parroquias, catedrales, monasterios, conventos y seminarios se convirtieran en un elemento más para dar a conocer la labor de la Iglesia a lo largo de los tiempos.

En relación a los seminarios, será a partir del Concilio de Trento cuando se comiencen a erigir estos centros que surgen para dar una formación integral al clero. En el capítulo i8 del Decreto de Reforma se instituyen los seminarios, disponiendo que en todas las iglesias catedrales, metropolitanas o superiores, según los recursos económicos y según sea la extensión de la diócesis, se establezca un colegio o seminario para la educación de los niños y jóvenes y la formación en disciplinas eclesiásticas ${ }^{15}$. Se iniciaba entonces la trayectoria histórica y, por extensión, archivística de una nueva institución.

En el caso particular de Badajoz se observa la preocupación por la instrucción de los clérigos y los diferentes modos de establecerla. Pero la escasez de rentas hizo demorar la creación del Seminario. Para su puesta en marcha serán de suma importancia los legados y mandas pías ${ }^{16}$ que se constituyeron para tal fin. La más importante, sin lugar a dudas, la obra pía del canónigo de la catedral Rodrigo Dosma, que cedió sus casas de morada para la erección del Seminario,

pp. 89-IO8; Martín Hernández, F. J.: Los Seminarios españoles en la época de la Ilustración. Ensayo de una pedagogía..., op. cit.; Quintana Miranda, P. M.: Historia del Seminario Conciliar de Canarias, Canarias, Anroart ediciones, 2006; SUBIRA I BLASI, E.: El Seminari de Barcelona (I593-1917): aportació per a una anàlisi de la infuència de la formació del clergat, Barcelona, Publicacions de l'Abadia de Montserrat, 1993; Vergara Ciordia, J.: Historia y pedagogía del seminario conciliar..., op. cit.; VerGARA CIORDIA, J.: «Mentalidad cristiana y pensamiento pedagógico de la Iglesia en España...», op. cit.

is Cristiani, L.: «El Concilio de Trento (I5i8-i534)», en Fliche, A. y Martin, V. (dir.): Historia de la Iglesia, t. XIX, Valencia, Edicep, 1977, pp. 24I-243.

${ }_{16}$ Instituciones desarrolladas con autoridad de juez ordinario y fundación de rentas, con algunas obligaciones, especialmente misas. 
ANÁLISIS DE LAS SERIES DOCUMENTALES PARA EL ESTUDIO DE LA HISTORIA DE LA EDUCACIÓN EN LOS ARCHIVOS HISTÓRICOS DE SEMINARIOS ... AGUSTÍN VIVAS, FRANCISCO GONZÁLEZ Y GUADALUPE PÉREZ

como consta en el Libro de Fundación. Se instituye el Seminario, el 26 de mayo de I664, siendo obispo de la diócesis Jerónimo Rodríguez de Valderas, según refleja el título 27 de las Constituciones ${ }^{17}$, aunque se tiene constancia de que el 3 de mayo ya estaban los primeros colegiales en su interior.

$\mathrm{El} \operatorname{archivo}^{18}$ se crea a la vez que se instituye el Seminario, suponiendo una ingente producción de documentos. Veamos unas líneas que así lo demuestran:

En el lugar y parte que para este efecto de ser Archibo, se señalare, se pondrán tres cerraduras y llaves diferentes, las quales se tendrán las mismas personas, que esta dicho han de tener las del Arca: $Y$ en casso que qualquiera de ellas enfermare o hiciere ausencia del Colegio entregará unas y otras en presencia de la Capilla al que le hubiere de suceder en el oficio.

En el dicho Archibo se han de guardar todos los papeles pertenecientes a la fundación y erección del Colegio; los Titulos de las Uniones y agregaciones de los Beneficios Simples y los de qualesquiera otra hacienda y Vienes que finalmente todos los papeles necesarios para guarda del derecho del Colegio. Y anssimesmo se pondrán las quentas que el Prelado tomare de la Hacienda del Colegio con todos los recaudos, para su verificación se presentaron.

Y tendrasse un libro dentro del dicho Archibo en que aya razón de todos los Papeles que en el hubiere y de los que se sacaren con dia, mes y año y firma del que los recibiere para que le vuelva o de razón del.

Ha de haver otro libro en que se escriban las entradas de Rectores y Colegiales, y de cómo juraron con día, mes y año y los traslados de las probissiones que pressentaren. En otro libro se escriban las ausencias que el Rector y Colegiales hicieren, y con qué licencia, por quanto tiempo, y ansi mismo se escriba el día que volvieron ${ }^{19}$.

En líneas generales, el archivo del Seminario contiene la documentación producida y recibida por la entidad en el trascurso de su actividad educativa, litúrgica, pastoral y la derivada de la conservación y gestión de su patrimonio; así como la de otras instituciones (colegios-seminarios) dependientes de él, todas hoy desaparecidas.

El fondo histórico del archivo queda constituido de la siguiente forma: fondo del Seminario Diocesano de San Atón, fondo del Colegio-Seminario de San Benito (Villanueva de la Serena), fondo del Colegio-Seminario Nuestra Señora de la Coronada (Villafranca de los Barros), fondo de los Seminarios de Elvas y Olivenza, fondo musical y fondo colecciones.

En un primer momento la documentación se encontraba dispuesta en legajos que fueron adaptados en cajas archivadoras para su mejor conservación y custodia. Una vez revisados, la documentación fue cotejada con un catálogo descriptivo, que había sido confeccionado por el canónigo archivero Pedro Rubio Merino. En base a ello se confeccionó un cuadro de clasificación, adaptándolo a la

17 Rubio Merino, P.: El Seminario de San Atón. I664-1964, Madrid, Artes Gráficas Maribel, 1964, p. 328.

${ }_{18}$ En adelante Asмmв.

19 ASmmb, Constituciones, título 27. 

DE LA EDUCACIÓN EN LOS ARCHIVOS HISTÓRICOS DE SEMINARIOS ... AGUSTÍN VIVAS, FRANCISCO GONZÁLEZ Y GUADALUPE PÉREZ

Norma ISAD (G), que permite respetar la ordenación establecida. Se presenta este cuadro dividido en seis grandes secciones, de acuerdo a las Constituciones del centro y al Reglamento interno; así como a la propia reglamentación canónica.

3.2. Análisis educativo a través de los cuadros de clasificación de seminarios: el ejemplo del archivo del Seminario Metropolitano San Atón de Badajoz

El cuadro de clasificación diseñado para el archivo del Seminario Metropolitano de San Atón, así como de los fondos dependientes en él custodiados, es una herramienta documental que permite el establecimiento de un instrumento descriptivo de carácter simplista que atiende a lo múltiple y heterogéneo de la documentación y a los fondos que sirve; los cuales se dilatan en el tiempo desde el siglo XIv hasta nuestros días, si tenemos en cuenta no sólo los fondos históricos de la entidad, sino también su documentación más reciente.

\section{I.o GOBIERNO}

\section{CUADRO DE CLASIFICACIÓN}

I.OI Documentación Episcopal

I.or.or Bulas

I.OI.02 Constituciones

I.0I.03 Libro Actas de Visita

I.0I.04 Libro Decretos Episcopales

I.0I.05 Libro Doc. Obispo y Obispado

I.oı.06 Libro Fundación Seminario

I.0I.07 Libro Inventario Obispado

I.or.08 Reglamentos

I.02 Documentación Rectorado

I.02.0I Actas Seminario

I.02.02 Libro de Actas Académicas

2.0 SECRETARÍA

2.0I Asuntos Académicos

2.or.or Actas de Exámenes

2.0I.02 Becas

2.0I.03 Expedientes de Conducta

2.01.04 Listado de Alumnos

2.0I.05 Matrículas

2.0I.06 Solicitud/Justificantes

2.02 Asuntos Generales

2.02.0I Cédulas Reales

2.02.02 Certificaciones

2.02.03 Correspondencia

2.02.04 Expedientes Personales

2.02.05 Informaciones

2.02.06 Planes de Estudios 
3.0 ADMINISTRACIÓN

3.OI Administración General

3.01.01 Correspondencia

3.01.02 Cuentas

3.01.03 Obras

3.01.04 Pagos

3.01.05 Recibos/Justificantes

3.01.06 Salarios

3.02 Bienes

3.02.0I Censos

3.02.02 Cuentas

3.02.03 Escrituras

3.02.04 Inventario de Bienes

3.02.05 Libro Becerro

3.03 Obras Pías

3.03.0I Administración

- Cuentas

- Inventario de Bienes

- Libro de Cuentas

3.03.02 Obras Pías

- Arias de Hoces

- Bravo de Laguna

- Diego Hernández

- Duque de Béjar

- Feria

- Fonseca

- Francisco López Chávez

- Francisco Mejías

- Josefa Vicente Rino

- Marqués de Lapilla

- Pedro Casas Guerrero

- Rodrigo Dosma

- Somoza Ribera

4.0 FONDOS COLEGIOS-SEMINARIOS DEPENDIENTES

4.or Fondo Seminario Menor Elvas-Olivenza

4.or.or Censos

4.0I.02 Correspondencia

4.01.03 Cuentas

4.01.04 Foro de Trigo

4.0I.05 Informes

4.02 Fondo Seminario Menor de Nuestra Señora de la Coronada.

Villafranca de los Barros

4.02.0I Cuentas

4.02.02 Notas

4.03 Fondo Seminario Menor de San Benito. Villanueva de la Serena

4.03.0I Cuentas 


$$
\begin{aligned}
& \text { 4.03.02 Escrituras } \\
& \text { 4.03.03 Matrículas } \\
& \text { 4.03.04 Notas } \\
& \text { 4.03.05 Solicitudes }
\end{aligned}
$$

\subsection{FONDO MUSICAL}

5.OI Música sacra

5.02 Música profana

\subsection{FONDO COLECCIONES}

6.or Fotografías

6.02 Monedas

Es momento ahora de ir desgranado muy brevemente, porque no es el cometido fundamental de este trabajo, el cuadro de clasificación del archivo del Seminario de San Atón para ir conociendo, al menos someramente, su documentación.

El cuadro de clasificación se constituye de 6 grandes secciones: gobierno, administración, secretaría, fondos dependientes, archivo musical y colecciones.

- La primera de las secciones, GOBIERNO, hace referencia a la documentación que ha generado el Seminario en su propia gestión interna, haciendo alusión a los elementos constitutivos más importantes de la entidad. Fundamentalmente esta documentación es la proveniente del obispo (con potestad para dirigir el funcionamiento de la entidad) y del rector (como máximo responsable del Seminario).

En relación a la subsección obispo destacamos: bulas (cuya misión principal era llevar el adoctrinamiento papal al Seminario); constituciones (leyes fundamentales por las que se regía el Seminario, se custodian las de 1783-1797, del obispo Solís y Gragera, y las de I849, del obispo Rodríguez Obregón); libro de fundación (documento más importante desde el punto de vista histórico custodiado en el archivo); reglamentos (disposiciones específicas para regular la actividad cotidiana del Seminario, entre los años I863 a I926, dictaminadas por el obispo Pantaleón Monserrat).

En relación a la subsección rector destacamos: actas de seminario (documentos que recogen los puntos discutidos y acuerdos adoptados en las diferentes reuniones convocadas por el rector entre I853 y 1934); actas académicas (documentación sobre formación interdisciplinar de los seminaristas por medio de conferencias teológicas o filosóficas).

- La segunda de las secciones, SECRETARÍA, da cabida a la parte más funcional de los seminarios. Como entidades educativas que son, van a establecer una clara distinción entre una secretaría general, que puede ser extrapolada a cualquier otra entidad o empresa, y una secretaria académica, que va a gestionar asuntos específicamente relacionados con la docencia. 
ANÁLISIS DE LAS SERIES DOCUMENTALES PARA EL ESTUDIO DE LA HISTORIA DE LA EDUCACIÓN EN LOS ARCHIVOS HISTÓRICOS DE SEMINARIOS ... AGUSTÍN VIVAS, FRANCISCO GONZÁLEZ Y GUADALUPE PÉREZ

En relación a la subsección asuntos académicos destacamos: actas de exámenes (documentos que recogen ordenadamente los diversos exámenes que se realizaron en este Seminario entre I858 y 1930); becas (relaciones de alumnos que gozaron de este privilegio para poder cursar estudios durante los siglos XIX y xx); expedientes de conducta (informes específicos elaborados por los párrocos que cada uno de los alumnos debían presentar al obispo y al rector para poder ingresar en el Seminario. Se custodian como documentos aislados, dado que solían formar parte de un expediente completo, desde i862 a 1908); listado de alumnos (relación ordenada de los alumnos del Seminario entre I853 y 1895); matrículas (registros de alumnos que cursaron sus estudios en el Seminario desde 1793 a 1930); solicitudes/justificantes (súplica o solicitud informando de los deseos que llevan a los seminaristas a querer ingresar en este centro desde I868 a I889).

En relación a los asuntos generales, es decir, la secretaría general, aparecen documentos de variada índole que surgen del funcionamiento diario del propio Seminario. Muy destacables son: las Cédulas Reales que se conservan de 1767 a I771, emitidas por el rey Carlos III; un nutrido conjunto de certificaciones de I828 a I904; abundantísima correspondencia; expedientes personales con un amplísimo volumen y una dilatada distribución cronológica (I853-1923); e informaciones de alumnos (1683-1853).

- La tercera de las secciones, ADMINISTRACIÓN, está relacionada con las actividades encaminadas a la gestión de los bienes del Seminario, así como de los colegios dependientes de él.

En relación a la subsección administración general da cabida a la documentación contable de carácter más general. Destacaremos: cuentas y justificantes de pagos (son dos series documentales que nos van a permitir trazar estudios de la economía del Seminario, pero también de aspectos más amplios relacionados con la alimentación, sanidad, sociología, etc., desde 1797 a 1932); obras (documentación relativa a obras realizadas en el Seminario desde i893 a I93I: planos, certificaciones, bocetos, informes son algunos de los documentos que la integran); salarios (documentación relativa a los sueldos de los trabajadores del Seminario entre I830 y i857. Su análisis, además de cuestiones económicas, nos permite trazar el organigrama de la entidad).

En relación a los bienes destacaremos: los censos (el Seminario de Badajoz fue destinatario de algunos de ellos, como indica la documentación conservada desde I464 a I92I, permitiendo el estudio de este procedimiento, muy habitual en épocas pasadas, con un volumen documental ciertamente significativo); escrituras (el archivo custodia un amplio volumen de escrituras tanto de venta, compraventa como de permuta desde el siglo xv); inventario de bienes (documentación acreditativa de los diferentes bienes con los que el Seminario ha contado a lo largo de su historia. Su distribución cronológica entre los siglos XVI y XvIII nos permite abordar estudios relativos a cuestiones artístico-patrimoniales donde encontraremos informes detallados); libro de becerro (recoge a mano los privilegios del Seminario para uso manual y corriente concedidos en el siglo xviII). 

DE LA EDUCACIÓN EN LOS ARCHIVOS HISTÓRICOS DE SEMINARIOS ... AGUSTÍN VIVAS, FRANCISCO GONZÁLEZ Y GUADALUPE PÉREZ

En relación a las obras pías debemos señalar que en el archivo se custodia documentación relativa a trece mandas pías. Su volumen es amplísimo, al igual que lo es su distribución cronológica desde I599 a I885, y permite el estudio pormenorizado de las siguientes obras pías: Arias de Hoces, Bravo de Laguna, Diego Hernández, Duque de Béjar, Feria, Fonseca, Francisco López Chavez, Francisco Mejías, Josefa Vicente Rino, Marqués de la Lapilla, Pedro Casas, Rodrigo Dosma, Somoza Ribera.

- La cuarta sección, FONDOS COLEGIOS-SEMINARIOS DEPENDIENTES, da a conocer documentación de los colegios-seminarios que dependieron del de Badajoz y que se crearon en la diócesis para dar formación a niños y jóvenes de poblaciones lejanas a la ciudad de Badajoz, donde se ubicaba el Seminario.

Fondo Seminario Menor Elvas-Olivenza: en la ciudad de Elvas se estableció un seminario que debido a la insuficiencia de sus rentas no pudo subsistir durante mucho tiempo y el obispo, para poder llevar a cabo la instrucción de sus diocesanos, erigió una cátedra de Moral y otra de Instituciones Canónicas en Olivenza. Destacamos su documentación sobre censos, correspondencia, cuentas, foro de trigos e informes. Toda ella comprendida entre los siglos XVIII y XIX.

Fondo Seminario Menor de Nuestra Señora de la Coronada: bajo el episcopado del obispo Ramón Rodríguez se instala un seminario menor en esta localidad que permanece abierto entre 1924 y 1939. Destacamos su documentación sobre cuentas y notas de alumnos.

Fondo Seminario Menor de San Benito: bajo el episcopado del obispo Fernando Ramírez, se adecúa para seminario menor el Palacio de los Priores de Magacela, permaneciendo activo de I884 a I892. Destacamos su documentación sobre cuentas, escrituras, notas, matrículas (cuya distribución es la más amplia desde I884 a I89I) y solicitudes.

- La quinta sección, FONDO MUSICAL, se compone de 90 partituras de música sacra y profana. Su estudio enmarcará la promoción musical en muchos de los pueblos de la región, puesto que gran parte los directores de corales adquirieron esta formación en el Seminario.

- La sexta sección, FONDO COLECCIONES, queda integrada por dos grandes subsecciones que se dedican a la fotografía y a las monedas. Estas colecciones, muy especialmente la de monedas, de más de 5.000 piezas, son un elemento más que atestigua la importancia del fondo archivístico del Seminario de San Atón.

Esta rica documentación sirve de base al investigador que se acerque a sus fondos. Varios son los contenidos que se pueden vislumbrar desde la descripción previa que hemos realizado de sus fondos. 
ANÁLISIS DE LAS SERIES DOCUMENTALES PARA EL ESTUDIO DE LA HISTORIA DE LA EDUCACIÓN EN LOS ARCHIVOS HISTÓRICOS DE SEMINARIOS ... AGUSTÍN VIVAS, FRANCISCO GONZÁLEZ Y GUADALUPE PÉREZ

El presente trabajo se fija en los relacionados con la pedagogía y educación desde el siglo xvir al xx. Describiremos el patrimonio documental conservado y que está al servicio de investigaciones histórico-pedagógicas.

\section{Contenidos educativos y pedagógicos en el archivo del Seminario San Atón}

Atendiendo al cuadro de clasificación anteriormente expuesto nos adentramos en el análisis de las secciones, subsecciones y series documentales en las que podemos encontrar documentación relativa a la educación en el Seminario.

- i.o GOBIERNO: el concilio de Trento dejaba en manos del obispo la dirección y guía de sus seminarios. En su ayuda, colaboración y representación se encontraba la figura del rector. La dirección y gestión educativa del Seminario estarían en manos de ambos. Ésta será la sección más importante que habrá de ser consultada para enmarcar cualquier investigación educativa.

I.or Documentación episcopal: para comprender qué objetivos educativos se pretendían alcanzar en el Seminario de Badajoz es de obligado cumplimiento acudir a esta subsección. Las líneas vertebradoras de la formación ofrecida por el prelado quedarán recogidas aquí. Entre la documentación destacamos tanto el libro de fundación como las diversas constituciones y decretos ordenados al buen funcionamiento del establecimiento.

I.oI.02 Constituciones: son éstas las que determinan la misión, visión y finalidad del Seminario, además de detallar la función de cada uno de los integrantes del centro. De esta documentación resaltamos las promulgadas por el obispo Solís y Gragera entre 1783-1797 y las del obispo Francisco Javier Rodríguez Obregón de i849. Ambas hacen mención específica a la función y cargos existentes en el Seminario, entre los que se encuentran el rector, vicerrector y catedráticos, además de las disposiciones respectivas a los alumnos internos y externos.

I.0I.03 Actas de visita: los libros de actas de visitas recogen las preceptivas visitas pastorales que los obispos realizaban al Seminario. Detallan la visión personal del prelado respecto al funcionamiento, organización y estado general educativo del seminario en la fecha de su gobierno. Entre 1900 y 1906 se realizan dos visitas pastorales en las que se felicita al centro por el buen ambiente que han podido observar los respectivos prelados.

I.01.04 Decretos episcopales: entre los aspectos pedagógicos que se encuentran en esta serie encontramos nuevas directrices educativas del obispo Fernando Ramírez Vázquez orientadas al compromiso de los seminaristas con su propia educación y su adhesión a la diócesis. Resulta muy interesante para entender la participación 
activa de los seminaristas en los procesos formativos, concluyendo su protagonismo real en la educación recibida.

I.or.o5 Documentación obispo y obispado: documentación referida al obispo Amador Merino Malaguilla respecto a normas de conducta y directrices formativas en $\mathbf{1 7 3 4}$. El obispo sostiene y orienta las directrices fundamentales del centro.

I.0I.06 Libro de fundación: se trata del documento más relevante en la historia pedagógica del seminario por ser la narración de los primeros pasos de la institución. Fundamental para datar cronológicamente los inicios educativos del centro, las personas que impulsaron su creación y las principales dificultades en su puesta en marcha.

I.or.08 Reglamentos: Los reglamentos custodiados tratan de adaptar a la época las normas establecidas por el Concilio de Trento. El obispo Pantaleón Montserrat en I863 adapta parte de las constituciones de su antecesor a las circunstancias más actuales. Este reglamento nos demuestra el interés del prelado por el Seminario y la aplicación de nuevas normas pedagógicas para nuevos tiempos.

I.02 Documentación rectorado: como dijimos anteriormente, la representación legal del obispo y del seminario recae en la figura del rector, quien llevará a buen término las directrices pedagógicas y educativas designadas para el Seminario.

I.02.OI Actas del Seminario: recoge la necesaria documentación de consulta para adentrarnos en la historia detallada de la institución y de los procesos educativos en ella desarrollados. Los libros de actas relatan las más significativas decisiones en cuanto al gobierno y a la estructura de los aspectos pedagógicos internos del seminario. Las fechas extremas son 1853-1934. Desde el punto de vista educativo, y como detalle, aparece la puesta en marcha del nuevo plan de estudios destinado a los seminarios tras el concordato entre Isabel II y la Iglesia católica en I85I.

I.02.02 Actas académicas: en la formación interdisciplinar de los seminaristas se encontraban las «academias», conferencias semanales que, guiadas por el rector y director de estudio, tenían como protagonistas a los propios seminaristas de la etapa filosófica y teológica. Este libro recoge un resumen de estas disertaciones y el modo de llevarlas a cabo. Nos muestran el elevado nivel cultural filosófico y teológico de los colegiales desarrollado mediante el método silogístico.

- 2.o SECRETARÍA: al adentrarnos en la segunda sección, nos encontramos con el mayor grueso de documentación educativa del Seminario. El carácter eminentemente formativo del centro hace que esta sección albergue gran parte 
ANÁLISIS DE LAS SERIES DOCUMENTALES PARA EL ESTUDIO DE LA HISTORIA DE LA EDUCACIÓN EN LOS ARCHIVOS HISTÓRICOS DE SEMINARIOS ... AGUSTÍN VIVAS, FRANCISCO GONZÁLEZ Y GUADALUPE PÉREZ

de la documentación que ha de estudiarse desde el punto de vista históricopedagógico.

2.0I Asuntos académicos: esta subsección acumula la documentación relativa a la matriculación y trayectoria académica de los alumnos, además de todo lo referido a las becas que facilitaban el acceso y la permanencia en el centro.

2.OI.or Actas de exámenes: relación de las notas expedidas por el profesorado a sus alumnos entre 1858 y 1930 . Se abre la puerta a estudio exhaustivo del modo de calificación del profesorado, de las observaciones marginales que apuntaban y que detallan la evolución académica de los alumnos, las cuestiones en las que algunos alumnos debían incidir para superar las materias, etc.

2.0I.02 Becas: el seminario, desde el punto de vista económico, no cerró sus puertas a los más necesitados. Es más, se podría afirmar, con la información contenida en esta serie, que fueron muchos los que pudieron acceder a estudios mediante el sistema de ayudas instituidas por los obispos. Esto repercutirá positivamente en la disminución del analfabetismo de la sociedad extremeña.

2.0I.03 Expedientes de conducta: el Seminario concebía la educación como un proceso más amplio a la mera exposición de contenidos que habrían de memorizarse. La dimensión integral de la formación ofertada hacía que en el período vacacional se hiciera un seguimiento de los alumnos y de los candidatos que presentaban sus solicitudes de ingreso. Los párrocos rellenan estos expedientes de conducta aportando información muy valiosa sobre el modo de vida de los colegiales durante su estancia familiar.

2.01.04 Listado de alumnos: el archivo custodia diferentes relaciones nominales de alumnos entre I853 y i895. Para el investigador esta serie aporta contenidos muy relevantes para su estudio: número de matrículas, procedencia de los alumnos, edad, nombre de los padres, nombres de los encargados en la ciudad para poderse poner en contacto con ellos, observaciones de variada índole. Los análisis resultantes mostrarán la influencia educativa del centro como referente en la región extremeña.

2.0I.05 Matrículas: mediante el análisis de estas matrículas se puede completar la relación de alumnos de la serie anterior y que recibieron educación en el Seminario. Se abre también la puerta al estudio de casos sobre algún curso o alumno particular, observando la relevancia social que muchos de los alumnos tuvieron a nivel civil y las relaciones personales creadas entre ellos mismos.

2.01.06 Solicitud/Justificantes: más documentación necesaria en la consulta del investigador que desee elaborar el listado completo de alumnos que pasaron por San Atón o que quiera realizar la trayectoria educativa de un alumno en particular. Se custodian 
solicitudes enviadas al obispo, informes del rector, expedientes de conducta, certificados médicos, etc.

2.02 Asuntos generales: la secretaría general debía publicar los diferentes planes de estudio que se impartían en el centro. Además se llevaba detallada cuenta de los certificados que los propios alumnos solicitaban o aquellos que se enviaban a las universidades a las que estuvo adscrita el Seminario. 2.02.02 Certificaciones: entre I828 y 1904 el secretario del centro detalla los múltiples certificados expedidos a los alumnos. De ellos se pueden sacar datos muy valiosos para seguir la trayectoria biográfica de los mismos. También hacen entrever las relaciones académicas con los diferentes centros universitarios a los que se agregó el Seminario.

2.02.03 Correspondencia: aquí encontramos, fundamentalmente, las solicitudes personales que los candidatos o alumnos enviaban al obispo para obtener beca o la misma licencia solicitada para presentarse a algún examen. Además se encuentra la correspondencia del obispo al rector y viceversa sobre temas relacionados con el Seminario, su funcionamiento o lineas educativas que habrían de implantarse. También localizamos los nombramientos de catedráticos de los distintos centros y las cartas de relaciones con otros centros académicos de la ciudad o de otras regiones. Esta serie ayuda al investigador en la descripción de los hechos que tuvieron que ver con la educación.

2.02.04 Expedientes personales: un elevado número de datos biográficos referidos al alumnado. Llama la atención por su amplitud, 42 cajas de expedientes personales de los alumnos. Los candidatos para ingresar al Seminario debían presentar una documentación previa que sería revisada por el obispo o por el rector. En líneas generales, salvo casos excepcionales, sus expedientes contaban con una solicitud previa del candidato dirigida personalmente al obispo o al rector (existen casos en los que dicha solicitud era firmada por el padre); la aprobación y visto bueno de los últimos responsables eran necesarios para la admisión del candidato. $\mathrm{Ha}-$ brían de presentar también un certificado de bautismo que acreditara la catolicidad del niño. Se incluye un certificado de buena conducta visado por el párroco donde residía habitualmente el candidato. Estos últimos datos nos dan una visión del contacto asiduo que existía entre seminario y parroquia y que ambos iban de la mano en la consecución de los fines educativos y su formación. Igualmente se adjuntaba un certificado médico que acreditara la ausencia de enfermedad contagiosa o infecciosa. En el caso de haber asistido a alguna escuela de gramática o haber cursado enseñanza privada en alguna de las escuelas rurales existentes en la provincia, añadían un certificado de dichos estudios. 
ANÁLISIS DE LAS SERIES DOCUMENTALES PARA EL ESTUDIO DE LA HISTORIA DE LA EDUCACIÓN EN LOS ARCHIVOS HISTÓRICOS DE SEMINARIOS ... AGUSTÍN VIVAS, FRANCISCO GONZÁLEZ Y GUADALUPE PÉREZ

Esta última documentación ayuda en la elaboración del mapa educativo de la provincia, puesto que sitúa las poblaciones en las que estas escuelas de enseñanza doméstica, privada o escuelas de gramáticas (dependiendo de la época que se estudie), además de proporcionar información sobre los directivos de dichas escuelas. Muchos de los candidatos incluían un certificado de pobreza y una solicitud de beca, lo cual aporta datos relevantes en cuanto a la contribución cultural del Seminario a una región eminentemente rural. En orden a una visión panorámica de aquel que se adentre en el estudio pedagógico de esta institución se hace necesaria la consulta de estos expedientes personales. Mediante ellos nos hacemos clara idea del número de alumnos que pasó por las aulas de San Atón, sus procedencias, en algunos casos la situación laboral de sus padres, cuál era su situación académica previa a la entrada al Seminario, incluso la situación económica de penuria que nunca impidió al centro ofrecer a la sociedad una educación de alto nivel mediante un sistema de becas sostenidas por el obispo y otros particulares. Así mismo relatan, con todo lujo de detalles, el modo de realizar el examen de grado en Teología que se acordó en el concordato de $185 \mathrm{I}^{20}$.

2.02.05 Informaciones: completa la sección anterior y da una visión cronológica previa: 1683-1853. Resulta imprescindible su consulta para hacerse una composición de lugar del alumnado de la época.

2.02.06 Planes de estudio: a partir del concordato de I85I, la titulación ofrecida por el Seminario se redujo al bachiller en Teología. Se había iniciado una nueva adaptación pedagógica que se llevó a cabo mediante la adaptación al nuevo plan. Esta documentación recoge también las preguntas y el modo de llevar a cabo los exámenes de grado en Teología. De esta serie se entresacan el listado completo de asignaturas que se cursaban en las diferentes etapas: Latín y Humanidades, Filosofía y Teología. A estos estudios se les añadían los que seguían la Carrera Menor, un modo más abreviado para acceder al ministerio sacerdotal.

- 3.0 ADMINISTRACIÓN: La puesta en marcha y el sostenimiento de un centro requieren una adecuada administración. El investigador que desee enmarcar las circunstancias económicas que acompañaron la vida educativa del Seminario necesitará consultar esta rica documentación.

Hacemos una descripción general de las tres subsecciones, sin profundizar en las distintas series documentales, debido a que la información que podemos utilizar para futuras investigaciones desde el punto de vista educativo, por su carácter económico, es menos abundante.

20 Véase anexo. 
3.OI Administración general: esta subsección está constituida, por un lado, por la correspondencia generada y referida a la economía propia del Seminario; por otro, por un significativo número de cajas que recogen todos los recibos de compras y ventas de la institución. Además podemos encontrar los recibos/justificantes de pagos emitidos por las empresas o instituciones con las que se mantuvo cualquier tipo de relación económica. Más nos interesa la serie de salarios que tiene la documentación relativa a los sueldos de los que trabajaron en el Seminario. Desde ahí podemos corroborar la presencia de rectores, catedráticos, personal de mantenimiento y otros servicios que prestaron sus servicios al centro. Estos datos resultan interesantes al investigador para poderlos comparar con los salarios de otros docentes en centros equiparables, además de comprobar los aumentos de sueldos que en repetidas ocasiones solicitaban los docentes debido al aumento del número de alumnos, gracias que concedía el obispo y que se reflejaban en sus salarios.

3.02 Bienes: en la documentación de esta subsección vamos a encontrar distintas series: censos, cuentas, escrituras, inventario de bienes y libro becerro. Mediante ellos se podrá comprobar cómo el sostenimiento económico de la amplia oferta educativa podía llegar sin dificultades a los más necesitados. También nos aportan los diferentes terrenos que poseía el Seminario y que sirvieron para intentar instaurar allí alguno de los centros agregados a San Atón (tal es el caso del castillo de Rocamador, propiedad, según uno de los inventarios, del Seminario).

3.03 Obras pías: las numerosas donaciones que se hicieron con la finalidad de iniciar el Seminario, además de las que se fueron fundando para tal fin, ayudan a explicar que la existencia del centro no era una empresa única del obispo, sino de toda la Iglesia Diocesana. La relación de los fundadores de estas obras pías tiene una relación muy directa con la posibilidad de que la empresa educativa del centro fuera llevada a buen término. El estudio de estas fundaciones abre las puertas al mecenazgo educativo de personajes ilustres de la época.

- 4.0 FONDOS COLEGIOS-SEMINARIOS DEPENDIENTES: relevante resulta toda la documentación custodiada en esta sección. Se trata de los aspectos pedagógicos y el funcionamiento ordinario de tres centros agregados al Seminario: el Seminario Menor Elvas-Olivenza, el Seminario de Nuestra Señora de la Coronada y el Seminario Menor de San Benito. La razón del inicio de estos centros estribaba en poder ofertar una educación reglada con tintes cristianos a la provincia, ubicando estos centros en puntos estratégicos geográficos para poder llegar así al mayor número de alumnos posibles. 4.or Fondo Seminario Menor Elvas-Olivenza: situado en un primer momento en la ciudad portuguesa de Elvas, lindando con la parte occidental de la provincia de Badajoz, el Colegio se abrió en el siglo xviri. Su finalidad educativa era idéntica a la de cualquier seminario: educar religiosamente 
ANÁLISIS DE LAS SERIES DOCUMENTALES PARA EL ESTUDIO DE LA HISTORIA DE LA EDUCACIÓN EN LOS ARCHIVOS HISTÓRICOS DE SEMINARIOS ... AGUSTÍN VIVAS, FRANCISCO GONZÁLEZ Y GUADALUPE PÉREZ

a niños y jóvenes que manifestaran indicios de vocación. Esta documentación abriría las puertas a estudios transfronterizos relacionados con la educación. De esta subsección nos interesan, fundamentalmente, tres series documentales.

4.0I.02 Correspondencia: la dirección del colegio estaba en permanente contacto con el prelado, de quien dependía en sus últimas decisiones. Además, queda patente la estrecha colaboración con el Seminario San Atón, de quien dependía jurídicamente. Los aspectos pedagógicos del centro y los objetivos que habrían de conseguirse se entrevén en las líneas de estas cartas.

4.0I.03 Cuentas: el funcionamiento de la entidad era similar al del Seminario de Badajoz. Sus cuentas nos dan una visión muy similar, en cuanto a gastos e ingresos reflejados, entre ambos centros. De ellos podemos entresacar las personas que integraron el colegio durante su funcionamiento así como las motivaciones que llevaban a invertir en unas estructuras u otras.

4.0I.05 Informes: las solicitudes para poder realizar exámenes, las comunicaciones de la dirección al rector del seminario, los informes personales de los colegiales se recogen en esta serie documental. Del mismo modo que los expedientes personales son de necesaria consulta para el conocimiento de los alumnos de San Atón, esta serie es primordial para la investigación de los colegiales de Elvas-Olivenza.

4.02 Fondo Seminario Menor de Nuestra Señora de la Coronada: el 9 de septiembre de 1924 iniciaba su andadura este nuevo colegio al amparo de la legislación educativa española y del impulso que el obispo quería dar a las vocaciones sacerdotales. Se situaba este nuevo centro en la comarca de Tierra de Barros, casi en el centro de la provincia pacense. Una nueva oferta educativa que facilitaría el acceso a la educación. Dos serán las series documentales que se conservan.

4.02.OI Cuentas: aparte de la información que encontramos en los libros de matrículas anteriormente descritos y que recogen las calificaciones de los alumnos de este centro, se conservan las cuestiones relativas a la economía del centro.

4.02.02 Notas: las calificaciones de los colegiales en el último año de funcionamiento del centro, curso I929-1930, forman esta serie documental. El resto de las notas pueden ser consultadas en los registros de matrículas generales del Seminario San Atón.

4.03 Fondo Seminario Menor San Benito: sus inicios se remontan a I885, previa solicitud del prelado al gobernador civil mediante oficio para la creación del centro. La base jurídica residía en la posibilidad de creación de centros privados de segunda enseñanza establecida por reales decretos en fechas anteriores. Este nuevo centro estaba localizado en Villanueva de la Serena, al este de la provincia de Badajoz. Su localización geográfica facilitaba, 
nuevamente, el acceso a la enseñanza. De las series documentales, desde el punto de vista pedagógico, además de las recurrentes cuentas, nos interesan las siguientes.

4.03.03 Matrículas: recogen los registros de alumnos entre i884 y I89i. Estos datos se pueden corroborar con los libros de matrículas del seminario San Atón, donde también se les incluía por ser considerados seminaristas a todos los efectos.

4.03.04 Notas: los resultados académicos eran exhaustivamente recogidos en la secretaría y enviados también al rector del Seminario para que los archivara. La particularidad de ser agregados a San Atón obligaba a tener una única secretaría que custodiara estos documentos, lo cual no implicaba la duplicidad de estos registros en el centro donde se impartía docencia.

4.03.05 Solicitudes: en este caso se conservan algunas solicitudes sueltas de alumnos que, al igual que hemos atestiguado anteriormente, enviaban al obispo con el respectivo informe de conducta e informe médico, junto a la partida de bautismo. Estos datos nos ayudan a conocer la vida del alumnado del centro, procedencia, edad, padres...

Por lo que respecta a los centros dependientes/agregados al Seminario hemos de destacar que cumplieron muy dignamente la misión para la que fueron creados: educar religiosamente a niños y jóvenes que aspiraran al sacerdocio. La amplia extensión de la provincia y de la diócesis dificultaba la llegada de esta oportunidad educativa a otros pueblos periféricos. Fueron instaurados en enclaves geográficos que facilitaran el acceso de las zonas rurales. Favorecieron, además, la reducción del analfabetismo que llegó a puntos dramáticos especialmente en la región extremeña. El estudio de la trayectoria educativa y formativa de estos colegios nos da una visión más amplia del entramado educativo de la región.

- 5.0 FONDO MUSICAL: si importante es la docencia de las materias propias del currículum del Seminario, no es menos significativa la dada a la música sacra en la formación integral de los seminaristas. Las 90 partituras que custodian las 17 cajas de esta sección dan muestra del buena hacer en el terreno musical. Fiel reflejo de que se llevaron a cabo adecuadamente es la aparición en horarios y planes de estudio de un tiempo dedicado exclusivamente al canto sagrado. Los libros de actas hacen referencia también a la escolanía creada a mediados de siglo xx y que se hizo famosa por toda la nación. Este fondo musical abrirá el campo al estudio de músicos que pasaron por el Seminario, puesto que fue cuna e inicio de su andadura profesional.

- 6.o FONDO COLECCIONES: la historia pedagógica del Seminario Metropolitano San Atón se completa con pruebas gráficas que atestiguan, en su última época, la evolución y diversas actividades realizadas por sus alumnos. Dos subsecciones forman este fondo. 
ANÁLISIS DE LAS SERIES DOCUMENTALES PARA EL ESTUDIO DE LA HISTORIA DE LA EDUCACIÓN EN LOS ARCHIVOS HISTÓRICOS DE SEMINARIOS ... AGUSTÍN VIVAS, FRANCISCO GONZÁLEZ Y GUADALUPE PÉREZ

6.or Fotografías: la colección fotográfica del Seminario llega a ser fuente de documentación para el que pretenda realizar la historia pedagógica general o particular del establecimiento en la medida que atestigua la diversa variedad de actividades realizadas por los escolares durante su estancia. Fotografías de los diversos cursos académicos, excursiones, fiestas, espacios celebrativos componen esta subsección.

6.02 Monedas: donadas en su gran mayoría por el obispo Félix Soto Mancera adornaban parte de las estancias del Seminario y fueron conocidas por sus alumnos. Su influencia pedagógica estriba en el ambiente cultural que aportaba al centro, al ser la numismática una ciencia auxiliar de la historia y colaborar en un espacio educativo promotor de cultura.

\section{Conclusiones}

La Iglesia por medio de los seminarios pretendió desde mediados del siglo XvI homogeneizar la formación y aumentar el nivel intelectual de la generalidad del clero. Y se logrará, al menos en parte, con la creación de estas nuevas instituciones que desarrollarán una importante base humanística y una especial preparación filosófica que a todas luces era insuficiente hasta el momento.

En el caso particular del Badajoz, podemos afirmar que el Seminario fue un centro educativo de referencia en Extremadura desde mediados del siglo xix hasta los albores del Concilio Vaticano II. Los obispos que rigieron la diócesis pacense jugaron un papel primordial adaptando las directrices educativas generales a las necesidades de su Iglesia local.

El inicio del siglo xx vio despuntar notablemente la labor educativa de San Atón comparado con otros seminarios. Confluyeron en él un excelente grupo de profesores intelectuales y humanistas que hicieron destacar al de Badajoz frente al resto de España. Un nutrido número de alumnos fueron educados en el Seminario de Badajoz. La vivencia de las virtudes fue la nota dominante del proyecto pedagógico que se estableció para ellos en cada etapa. Además, el centro posibilitó el acceso a los estudios para los que carecían de medios económicos suficientes mediante un sistema de becas. Casi la totalidad de los pueblos de la provincia, a los que sumamos poblaciones aledañas, están representados en el listado de municipios que aportaron colegiales al Seminario: ello da muestra de que realmente era un centro de referencia en Extremadura.

Por todo ello, afirmamos la insigne labor educativa llevada a cabo en el Seminario de San Atón dando frutos mediante la integración de sus profesores y alumnos en la sociedad. Ellos fueron promotores de cultura y humanismo allá donde se insertaron, elevando el nivel cultural de una región marcada por la extremada pobreza educativa. Constatamos la escasez de estudios sobre educación y pedagogía que tomen como punto de partida los archivos de seminarios. Sí existe un mayor número de investigaciones de carácter generalista que las que se centran en el análisis específico de estas cuestiones, como se plasma en el estado de la cuestión. 

DE LA EDUCACIÓN EN LOS ARCHIVOS HISTÓRICOS DE SEMINARIOS ... AGUSTÍN VIVAS, FRANCISCO GONZÁLEZ Y GUADALUPE PÉREZ

El archivo del Seminario custodia documentación sobre cuestiones educativas y pedagógicas muy relevantes para el conocimiento de la institución y de la historia educativa de Extremadura entre los siglos XVII-XXI. Las investigaciones educativas de carácter histórico encuentran en nuestro archivo amplia y diversa documentación respecto a alumnos, profesores, objetivos pedagógicos, planes de estudio y principios educativos de la época. A través del cuadro de clasificación el acceso a las fuentes documentales del Seminario abre las puertas a sistemáticos conocimientos de la cultura extremeña, valorando el enriquecimiento cultural que aportó el centro a través de la educación integral que ofreció a los miles de alumnos que desde el siglo XVII han pasado por sus aulas. 
ANÁLISIS DE LAS SERIES DOCUMENTALES PARA EL ESTUDIO DE LA HISTORIA DE LA EDUCACIÓN EN LOS ARCHIVOS HISTÓRICOS DE SEMINARIOS ... AGUSTÍN VIVAS, FRANCISCO GONZÁLEZ Y GUADALUPE PÉREZ

\section{$\operatorname{Anexos}^{21}$}

Expediente de ingreso al Seminario de Lázaro Gamonal y Gamero. ASMMB, Sección Secretaría, caja iI

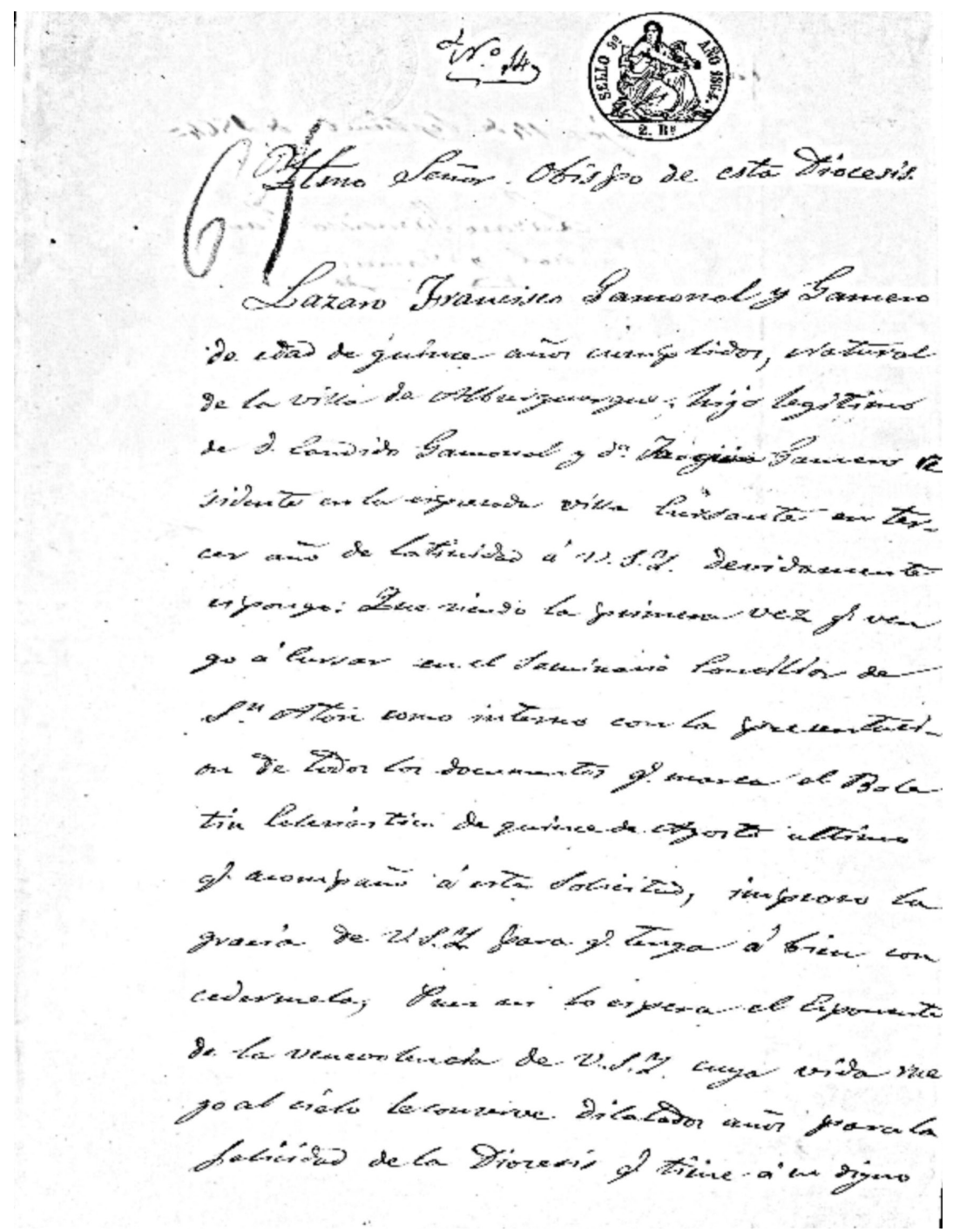

${ }^{21}$ El anexo que se expone a continuación es un expediente completo de uno de los miles de seminaristas que cursaron estudios en el Seminario de Badajoz. Es un formato tipo, que como tal nos permite establecer un patronaje para el resto de alumnos y conocer de primera mano la documentación requerida a los seminaristas para su ingreso, es decir, su expediente personal. Hay que destacar la importancia de estos documentos porque son los que nos permiten conocer los alumnos que accedieron a los procesos educativos impartidos en nuestro centro. 
ANÁLISIS DE LAS SERIES DOCUMENTALES PARA EL ESTUDIO DE LA HISTORIA DE LA EDUCACIÓN EN LOS ARCHIVOS HISTÓRICOS DE SEMINARIOS ... AGUSTÍN VIVAS, FRANCISCO GONZÁLEZ Y GUADALUPE PÉREZ

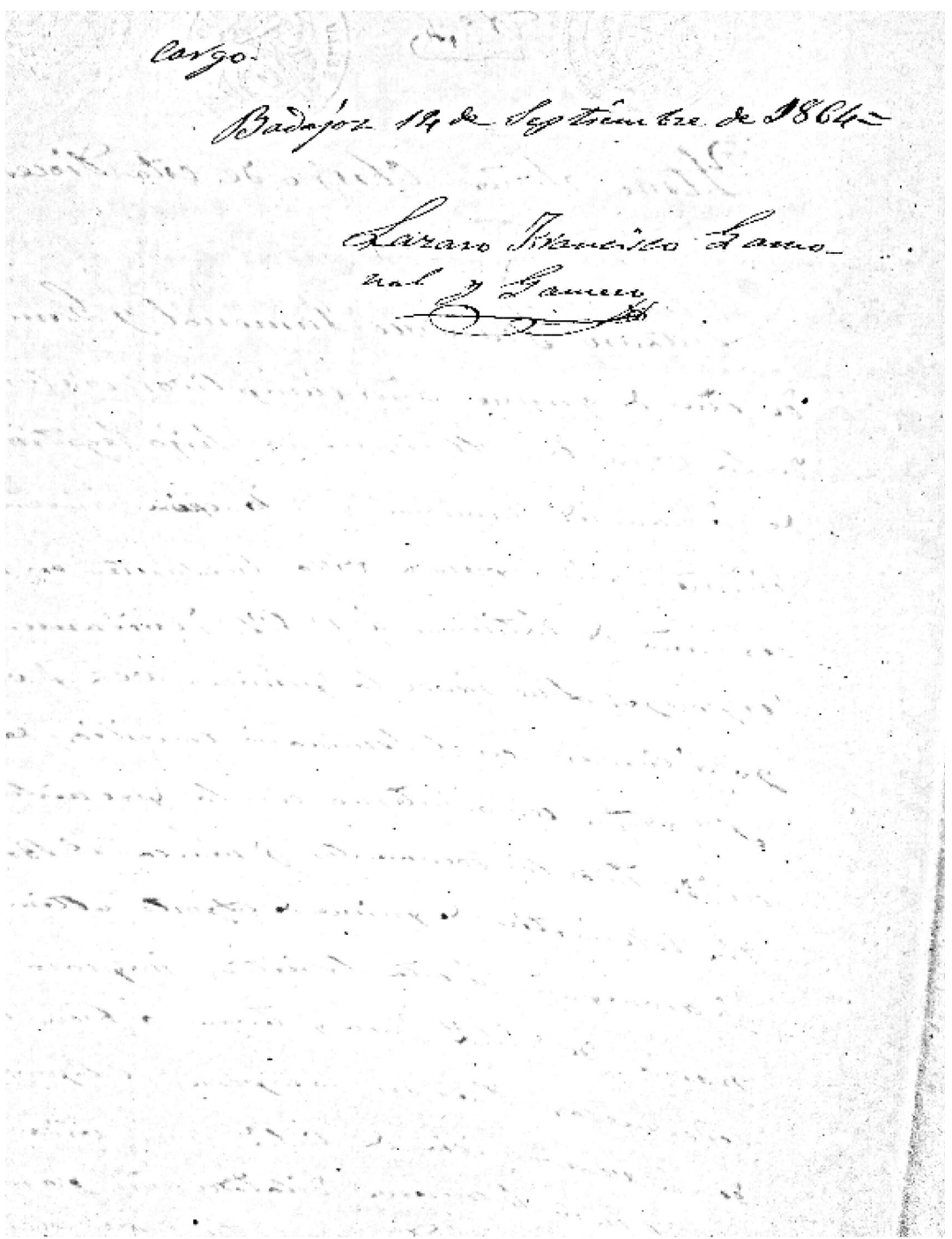

Solicitud manuscrita de Lázaro Gamonal y Gamero. 


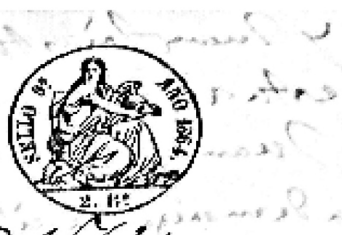

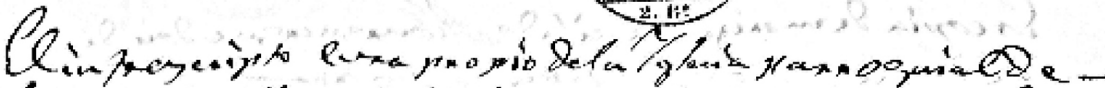

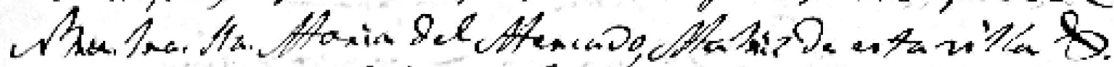

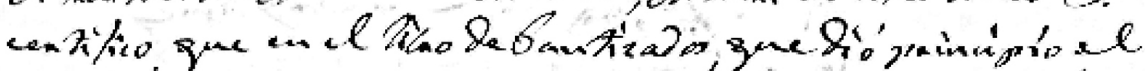

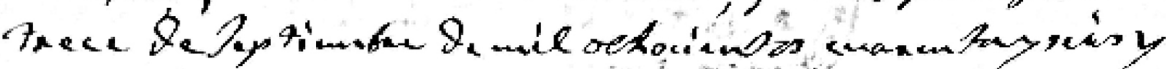

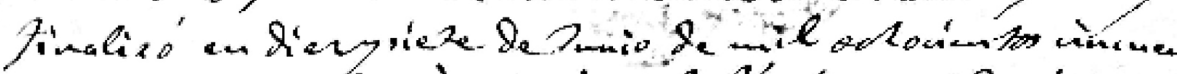

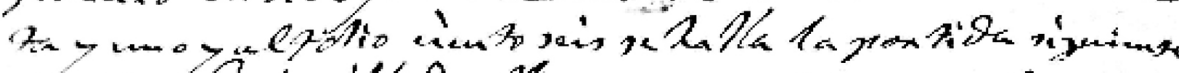

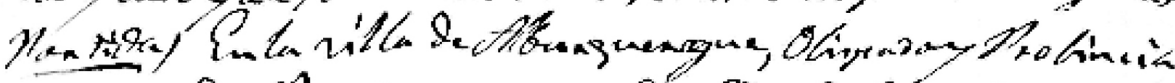

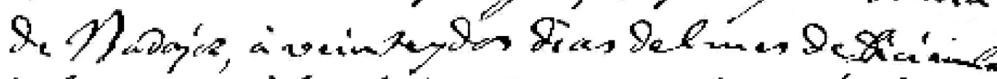

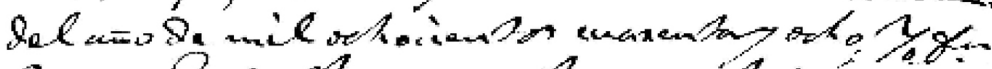

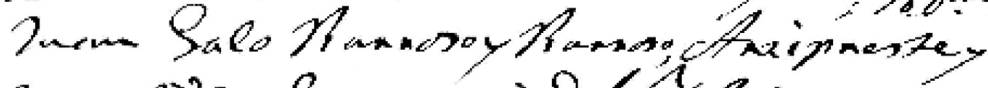

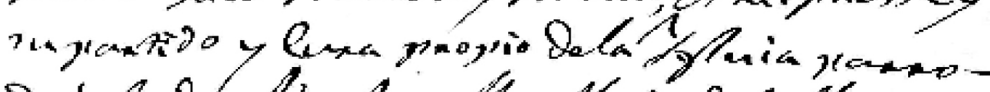

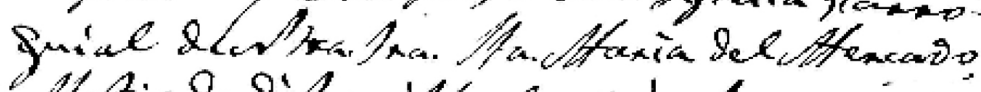

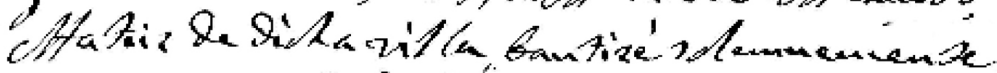

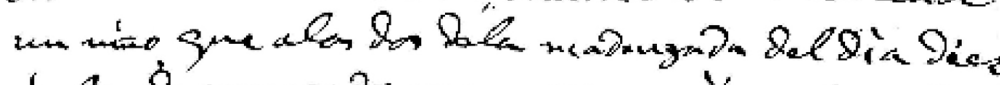

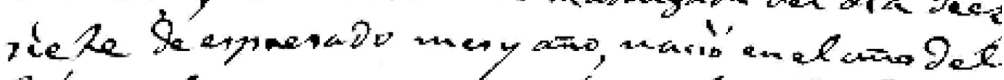

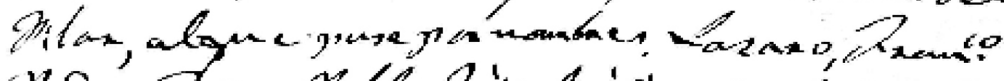

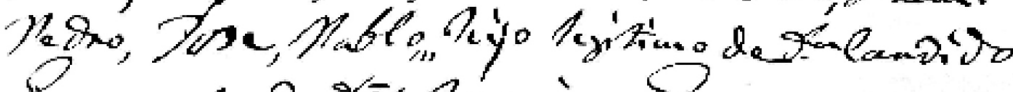

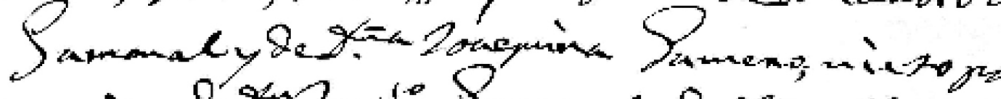

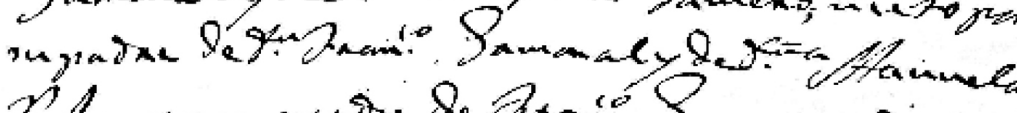

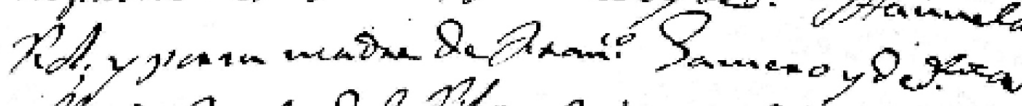

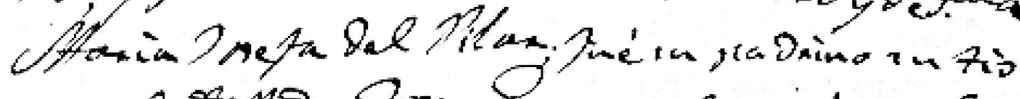

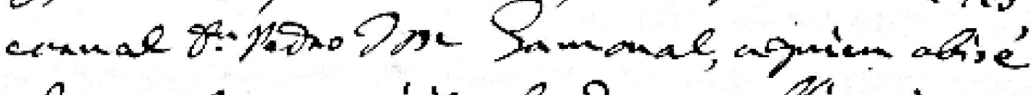

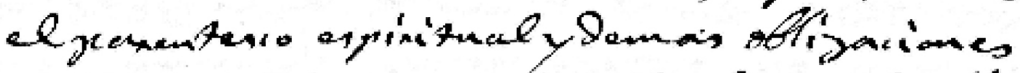

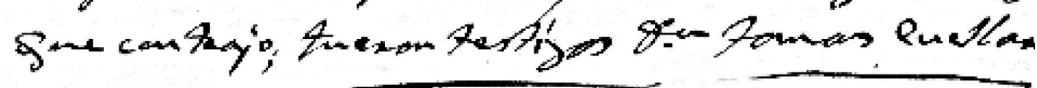

Partida de Bautismo del candidato. 


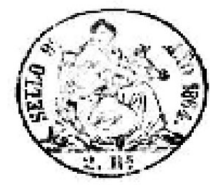

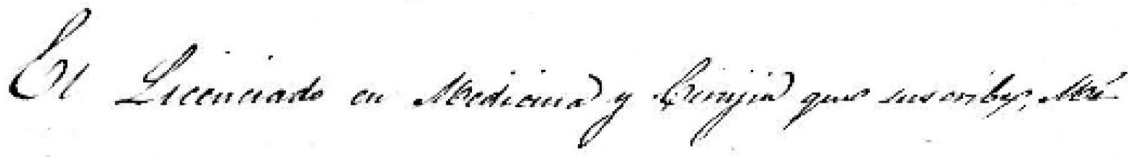

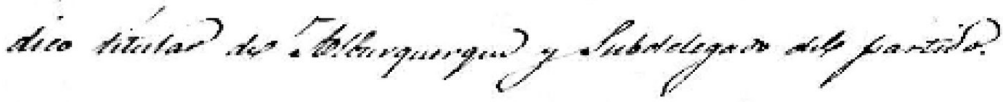

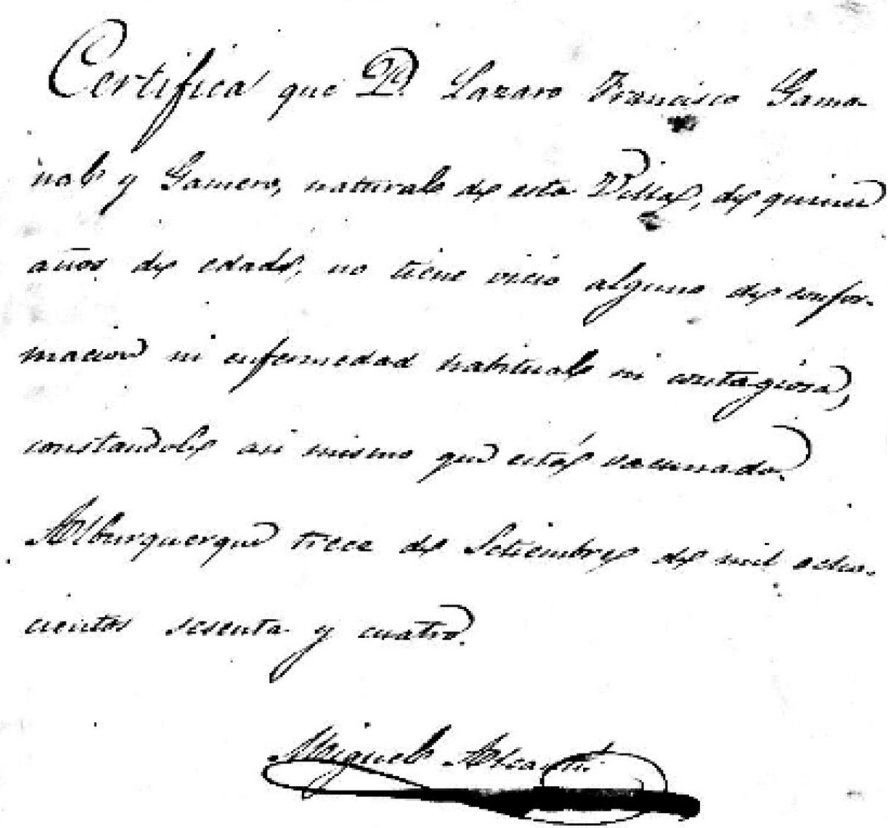

Certificado médico. 
ANÁLISIS DE LAS SERIES DOCUMENTALES PARA EL ESTUDIO DE LA HISTORIA DE LA EDUCACIÓN EN LOS ARCHIVOS HISTÓRICOS DE SEMINARIOS ... AGUSTÍN VIVAS, FRANCISCO GONZÁLEZ Y GUADALUPE PÉREZ

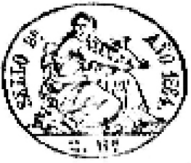

\section{3}

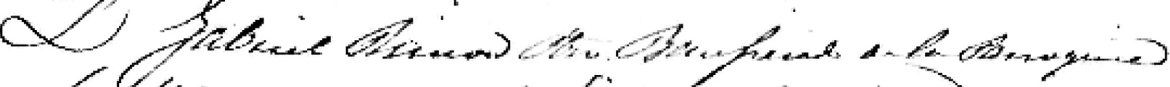

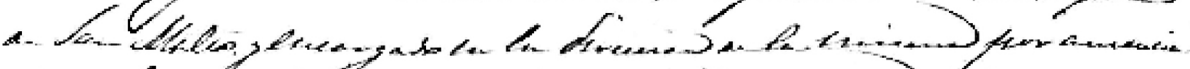
a C2)

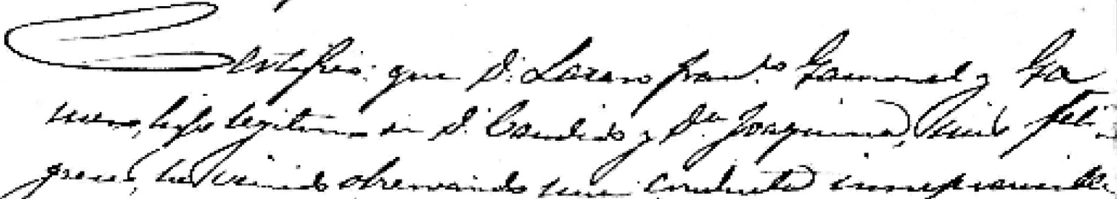

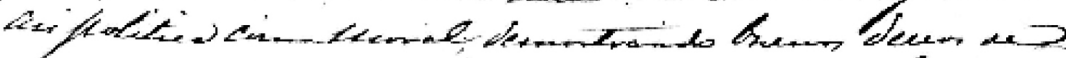

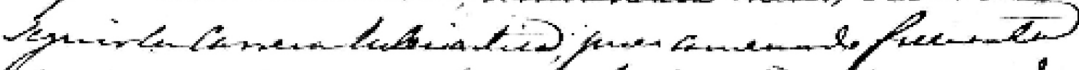

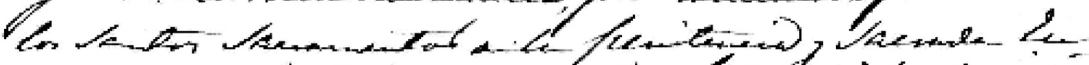

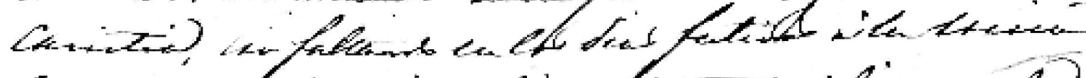

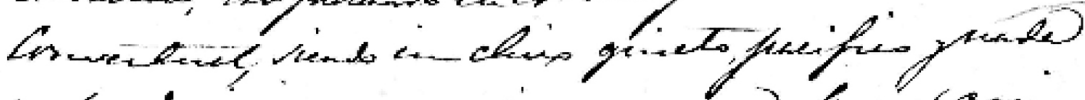

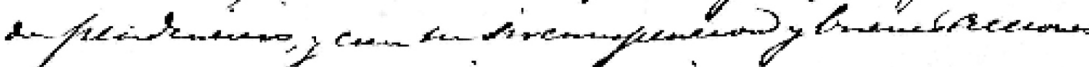

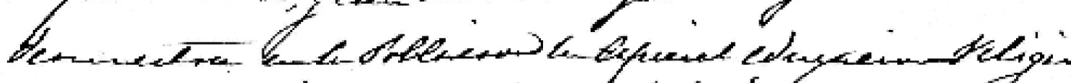

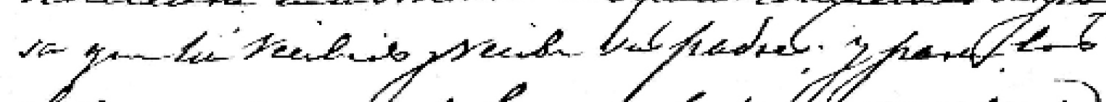

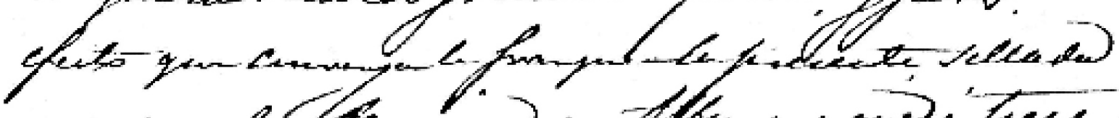

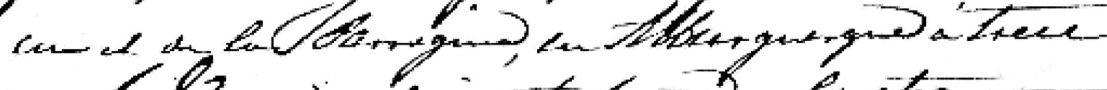

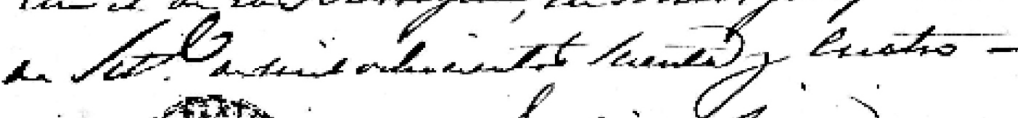

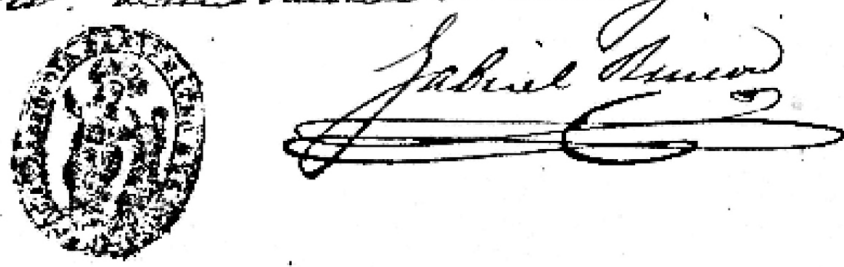

Certificado de buena conducta. 


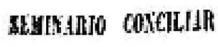

\section{SAN ATOH.}
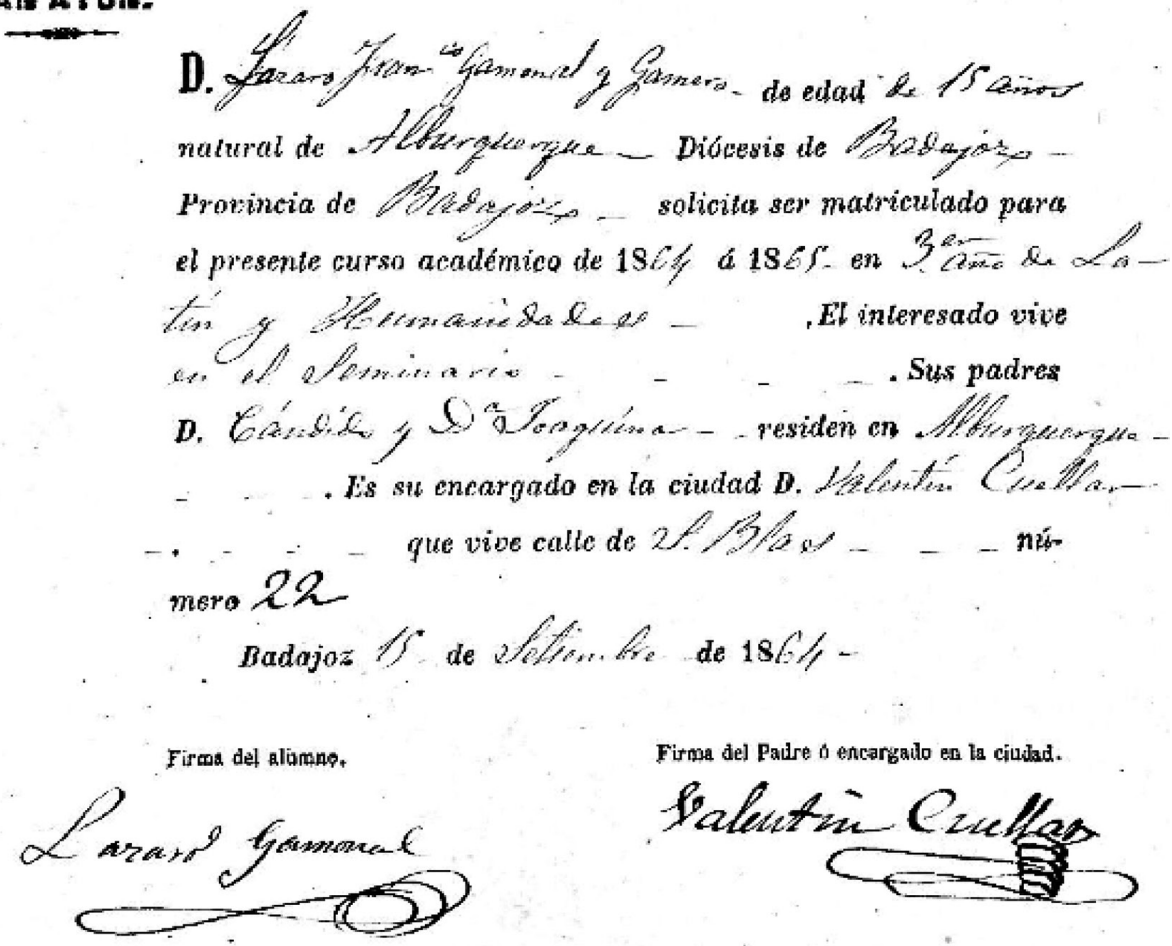

Firma del Paudre of encargalo en la ciudad.

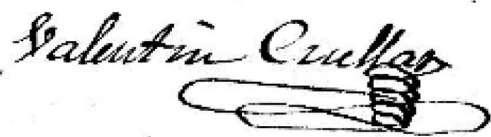

Solicitud del candidato mediante formato oficial. 